\title{
PENGARUH IKLAN SEPEDA MOTOR YAMAHA TERHADAP CITRA MEREK (STUDI PADA MAHASISWA POLITEKNIK LP3I MEDAN)
}

\author{
$\underline{\text { Risky Agustina, Riandani Rezki Prana, Suprianto }}$ \\ Alumni Sekolah Tinggi Ilmu Manajemen Sukma \\ Program studi Manajemen, Sekolah Tinggi Ilmu Manajemen \\ riandanirezki@gmail.com, supriantosu80@gmail.com
}

\begin{abstract}
The aim of this research is to know the influence of yamah motorcycle advertisement on brand image (study on Police student of LP3I Medan). The sample of this study is all members of the population used as a sample, sampling using a saturated sample is a sample determination technique when all members of the population used as a sample. Data analysis using simple regression test with model accuracy (classical assumption test), hypothesis test using coefficient of determination test $\left(R^{2}\right)$, partial test ( $t$ test), while data processing using SPSS 15. The result of research indicate that advertisement variable can not explain its existence to Brand image, in addition to the partial advertising variable does not affect the brand image.
\end{abstract}

Keywords: Advertisement and brand image

\section{PENDAHULUAN}

Kondisi persaingan yang mengharuskan pengusaha mampu menciptakan strategi pemasaran yang lebih efektif dan efesien dari pesaing, tentunya bukan hal yang mudah, dibutuhkan pemikiran dan ide yang bisa menarik perhatian orang banyak. Strategi pemasaran bisa dilakukan dengan adanya iklan dan citra merek. Iklan merupakan salah satu variabel dari bauran promosi dalam pemasaran yang sangat penting karena merupakan satu dari sekian banyak cara yang dapat digunakan oleh perusahaan untuk membawa dan memperkenalkan produk perusahaan masyarakat. Namun, citra merek yang kuat memungkinkan kepada konsumen bahwa dengan hanya menyebut namanya akan timbul harapan bahwa merek tersebut akan memberikan kualitas yang terbaik. Oleh karena itu dalam melaksanakan aktivitas penjualannya, sebuah perusahaan harus dapat merancang strategi pemasaran yang salah satunya menggunakan media periklanan, sehingga dapat mencapai tujuan perusahaan dalam meningkatkan pembelian konsumen terhadap produk tersebut. Periklanan (advertising) adalah suatu bentuk komunikasi media yang paling diandalkan untuk mempromosikan suatu barang atau jasa dan suatu iklan pun harus mudah dicerna oleh target konsumen.

Perumusan Masalah

Perumusan masalah penelitian ini yaitu apakah ada pengaruh iklan sepeda motor Yamaha terhadap citra merek (studi pada mahasiswa LP3I Medan)

\section{Batasan Masalah}

Penelitian ini hanya dibatasi pada mahasiswa/i reguler kampus Politeknik LP3I Medan unit Marelan angkatan 2015.

\section{Tujuan Penelitian}

Adapun tujuan dari penelitian ini adalah untuk mengetahui ada pengaruh iklan sepeda motor yamaha terhadap citra merek (studi pada mahasiswa Politeknik LP3I Medan)

\section{Manfaat Penelitian}

Manfaat dari penelitian ini adalah sebagai berikut:

1. Bagi Peneliti, menambahkan pengetahuan dan wawasan peneliti khusunya berkenan dengan adanya pengaruh iklan sepeda motor Yamaha terhadap citra merek (studi pada mahasiswa LP3I Medan)

2. Bagi Perusahaan, sebagai bahan masukan mengenai adanya pengaruh iklan sepeda motor Yamaha terhadap citra merek (studi pada mahasiswa Politeknik LP3I Medan) 
3. Bagi STIM Sukma, sebagai tambahan hasil penelitian yang dapat digunakan sebagai bahan rujukan dan dikembangkan lebih lanjut.

4. Bagi penelitian selanjutnya, sebagai bahan referensi khususnya yang berkaitan dengan iklan dan citra merek.

\section{METODE PENELITIAN}

\section{Jenis dan Sumber Data}

Data yang digunakan dalam penelitian ini adalah data primer dan data sekunder.

1. Data primer adalah data yang dikumpulkan langsung oleh peneliti seperti organisasi atau perusahaan (Trijono, 2015:36). Data primer berupa catatan hasil wawancara yang diperoleh langsung dari perusahaan melalui wawancara yang penulis lakukan. Selain itu, mengumpulkan data dalam bentuk catatan tentang situasi dan kejadian di perpustakaan.

2. Data sekunder merupakan data yang diperoleh dari pihak lain seperti BPS, BI, World Bank, IMF, FAO dan lainnya. BPS yang mengumpulkan data secara langsung dari masyarakat merupakan data primer bagi BPS. Akan tetapi data tersebut menjadi data sekunder bagi peneliti apabila tersebut menggunakan data yang dikumpulkan oleh BPS (Trijono, 2015:36). Data ini digunakan untuk mendukung informasi dari data primer.

Sumber data yang digunakan yaitu:

1. Data internal yaitu data yang didapat dari tempat penelitian dengan membagikan dan mengumpulkan kembali kuesioner kepada Mahasiswa LP3I Medan Cabang Marelan. Dimana data tersebut merupakan data mentah dan harus diolah sebelum dilanjutkan ke dalam skripsi.

2. Data eksternal adalah data yang didapat dari luar tempat penelitian seperti internet dan perpustakaan.

\section{Populasi dan Sample}

Menurut Sujarweni (2015:80) populasi adalah keseluruhan jumlah yang terdiri atas objek atau subjek yang mempunyai karakteristik dan kualitas tertentu yang ditetapkan oleh peneliti untuk diteliti dan kemudian ditarik kesimpulannya. Populasi yang diambil dalam penelitian ini adalah seluruh Mahasiswa reguler Politeknik LP3I Medan Cabang Marelan angkatan 2015-2016 yang berjumlah 53 mahasiswa/i.

Teknik pengambilan sampel dalam penelitian ini menggunakan sampel jenuh. Sampel jenuh menurut Sugiyono (2015:118) adalah bagian dari jumlah dan karakteristik yang dimiliki oleh populasi tersebut. Sampel dalam penelitian ini adalah seluruh populasi sehingga jumlah sampel dalam penelitian ini sebanyak 53 orang.

\section{Metode Pengumpulan Data}

Metode pengumpulan data yang digunakan dalam penelitian ini sebagai berikut:

1. Studi Dokumentasi: pengumpulan data yang dilakukan dengan mencari informasi berdasarkan dokumen-dokumen perusahaan yang berkaitan dengan penelitian

2. Kuesioner: metode pengumpulan data dengan membuat daftar pertanyaan dalam bentuk angket yang ditujukan kepada responden yang dijadikan sample.

3. Observasi: pengamatan dan melalui pengamatan secara langsung di Politeknik LP3I Medan Cabang Marelan

\section{Defenisi Operasional}

Berdasarkan rumusan masalah, maka variable-variable dalam penelitian ini dapat diidentifikasi sebagai berikut:

1. Variable bebas (variable independen) adalah variable yang mempengaruhi variable terikat, yang terdiri dari iklan $(\mathrm{X})$.

2. Variable terkait (variable dependen) adalah variable yang dipengaruhi oleh variable bebas yaitu citra merek (Y). 
Tabel Operasionalisasi Variabel Penelitian

\begin{tabular}{|c|c|c|c|c|}
\hline No & Variabel & Definisi & Indikator & Skala ukur \\
\hline 1. & Iklan (X) & $\begin{array}{l}\text { Semua bentuk terbayar } \\
\text { dari presentasi non } \\
\text { personal dan promosi } \\
\text { ide, barang atau jasa } \\
\text { melalui sponsor yang } \\
\text { jelas melalui media } \\
\text { cetak, } \\
\text { penyiaran, dan media } \\
\text { elektronik. }\end{array}$ & $\begin{array}{l}\text { 1. Perbandingan tayangan iklan } \\
\text { dengan kompetitor } \\
\text { 2. Bahasa iklan dan iklan yang } \\
\text { sesuai dengan kenyataan } \\
\text { produk } \\
\text { 3. Frekuensi/intensitas } \\
\text { dimedia }\end{array}$ & Likert \\
\hline 2. & $\begin{array}{l}\text { Citra } \text { Merek } \\
(Y)\end{array}$ & $\begin{array}{l}\text { sekumpulan asosiasi } \\
\text { merek yang terbentuk } \\
\text { di benak konsumen. }\end{array}$ & $\begin{array}{l}\text { 1. Citra Korporat } \\
\text { 2. Citra Produk } \\
\text { 3. Citra Pemakai }\end{array}$ & Likert \\
\hline
\end{tabular}

Sumber : Kotler dan Keller (2016:500), Novandri (2012:27), Rangkuti dalam Sangadji dan Sopiah

(2013:327) Biel dalam Sulistyari (2012:4)

Uji Validitas dan Reliabilitas

Menurut Sugiyono (2015:363) validitas merupakan derajad ketepatan antara data yang terjadi pada obyek penelitian dengan daya yang dapat dilaporkan oleh peneliti. Dikatakan valid jika nilai $r_{\text {hitung }} \geq r_{\text {tabel }}$ dan dikatakan tidak valid jika nilai $r_{\text {hitung }}<r_{\text {tabel }}$.

Menurut Sugiyono (2015:364) reliabilitas berkenaan dengan derajat konsistensi dan stabilitas data atau temuan. Dikatakan reliable jika nilai cronbach alfa $>0,5$ dan dikatakan tidak reliable jika nilai cronbach alfa $<0,5$

Metode Analisis Data

Metode analisis data yang digunakan dalam penelitian ini adalah metode deskriptif kuantitatif, sedangkan model analisis yang digunakan dalam penelitian ini adalah regresi sederhana.

$$
\mathrm{Y}=\mathrm{a}+\mathrm{bX}+\mathrm{e}
$$

Dimana:

$\mathrm{Y} \quad=$ Citra Merek

$a \quad$ Konstanta

$b \quad=$ Koefisien regresi variabel iklan

$\mathrm{X} \quad=$ Iklan

e $\quad=$ Eror of term (variabel yang tidak diteliti)

\section{Kerangka Berfikir}

Iklan adalah hal yang penting dalam mempromosikan suatu produk atau jasa dan iklan yang baik dapat meningkatkan nilai dari citra sebuah produk, penelitian sasetyo et al (2012) menunjukkan berpengaruh dari daya tarik iklan terhadap pembentukan citra produk pepsodent.

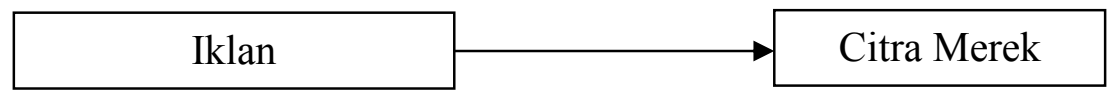

Gambar Kerangka Berfikir

Sumber: Sasetyo et al (2012) 


\section{Hipotesis}

Hipotesis merupakan jawaban sementara yang memerlukan penelitian lebih lanjut untuk mendapatkan kebenarannya.

Formula hipotesis penelitian ini adalah :

1. Jika $t_{\text {hitung }} \leq t_{\text {tabel }}$ maka $H_{0}$ diterima, $H_{1}$ ditolak, artinya secara parsial iklan tidak berpengaruh terhadap citra Merek,

2. Jika $t_{\text {hitung }}>t_{\text {tabel }}$ maka $H_{0}$ ditolak, $H_{1}$ diterima, artinya secara persial iklan berpengaruh citra Merek

Berdasarkan formulasi diatas, maka hipotesis penelitian ini adalah : ada pengaruh iklan Pengujian Hipotesis

sepeda motor Yamaha terhadap citra merek (studi pada mahasiswa Politeknik LP3I Medan)

a. Koefisien Determinasi $\left(\mathrm{R}^{2}\right)$

Koefisien determinasi $\left(\mathrm{R}^{2}\right)$ pada intinya mengukur seberapa besar kemampuan model dalam menerangkan variabel terkait. Semakin besar nilai koefisien determinasi (mendekati satu), maka dapat dikatakan bahwa pengaruh variabel bebas $(\mathrm{X})$ adalah besar terhadap variable terikat $(\mathrm{Y})$.

b. Uji Parsial (Uji t)

Kriteria:

Uji parsial (uji t) bertujuan untuk melihat pengaruh iklan terhadap citra merek dengan

1. Jika $t_{\text {hitung }} \leq t_{\text {tabel }}$ maka $H_{0}$ diterima, $H_{1}$ ditolak, artinya secara parsial penelitian ini tidak berpengaruh.

2. Jika $t_{\text {hitung }}>t_{\text {tabel }}$ maka $\mathrm{H}_{0}$ ditolak, $\mathrm{H}_{1}$ diterima, artinya secara parsial penelitian ini berpengaruh.

\section{HASIL DAN PEMBAHASAN}

\section{Uji Validitas dan Reliabilitas}

Uji validitas digunakan untuk melihat ketepatan instrument yang digunakan dalam penelitian. Instrument dikatakan valid jika nilai rhitung $>$ rtabel. Hasil validitas dari setiap instrument variabel penelitian adalah sebagai berikut:

Tabel Validitas instrument variabel iklan (X)

\begin{tabular}{|c|c|c|c|}
\hline \multirow{2}{*}{ Instrumen } & \multicolumn{2}{|c|}{ Nilai Validitas } & \multirow{2}{*}{ Kesimpulan } \\
\cline { 2 - 2 } & Rhitung & Rtabel & \\
\hline Iklan 1 & 0.680 & & Valid \\
\hline Iklan 2 & 0.640 & & Valid \\
\hline Iklan 3 & 0.392 & \multirow{2}{*}{0,2706} & Valid \\
\hline Iklan 4 & 0.292 & & Valid \\
\hline Iklan 5 & 0.571 & & Valid \\
\hline Iklan 6 & 0.638 & & Valid \\
& &
\end{tabular}

Dari tabel terlihat bahwa hasil pengujian masing-masing instrument variabel iklan (x) memiliki nilai r-hitung $>0,2706$, dengan demikian dapat disimpulkan bahwa secara keseluruhan instrument pernyataan dari variabel iklan yang digunakan valid.

Tabel validitas instrument variabel Citra Merek (Y)

\begin{tabular}{|c|c|c|c|}
\hline \multirow{2}{*}{ Instrumen } & \multicolumn{2}{|c|}{ Nilai Validitas } & \multirow{2}{*}{ Kesimpulan } \\
\cline { 2 - 2 } & rhitung & Rtabel & \\
\hline Citra Merek 1 & 0.385 & & Valid \\
\hline Citra Merek 2 & 0.305 & & Valid \\
\hline Citra Merek 3 & 0.642 & & Valid \\
\hline Citra Merek 4 & 0.610 & \multirow{2}{*}{0,2706} & Valid \\
\hline Citra Merek 5 & 0.407 & & Valid \\
\hline Citra Merek 6 & 0.632 & & Valid \\
\hline Citra Merek 7 & 0.335 & & Valid \\
\hline Citra Merek 8 & 0.301 & & Valid \\
& &
\end{tabular}


Dari tabel terlihat bahwa hasil pengujian masing-masing instrument variabel citra merek (y) memiliki nilai r-hitung $>0,2706$, dengan demikian dapat disimpulkan bahwa secara keseluruhan instrument pernyataan dari variabel citra merek yang digunakan valid.

Uji reliabilitas dilakukan untuk menjamin instrument yang digunakan merupakan instrument yang handal, konsisten dan stabil jika digunakan secara berulang-ulang pada waktu yang berbedabeda. Instrument dikatakan reliabel jika nilai cronbach alfa hitung $>$ cronbach alfa toleransi $(0,05)$. Hasil pengujian reliabilitas terlihat seperti berikut ini:

Tabel Hasil Reliabilitas Instrumen Penelitian

\begin{tabular}{|c|c|c|c|}
\hline No. & Variabel & $\begin{array}{c}\text { Nilai Cronbach's } \\
\text { Alfa }\end{array}$ & Kesimpulan \\
\hline 1 & Iklan (X) & 0.530 & Reliabel \\
\hline 2 & Citra Merek (Y) & 0.501 & Reliabel \\
\hline
\end{tabular}

\section{Hasil Uji Regresi Linier Sederhana}

Pengujian ini dilakukan untuk mengetahui pengaruh iklan sepeda motor yamaha terhadap citra merek (studi pada Politeknik LP3I Medan). Berikut ini tabel hasil pengujian regresi linier sederhana pada masing-masing variabel yaitu:

Tabel Hasil Uji Regresi Linier Sederhana

Coefficients $^{\mathrm{a}}$

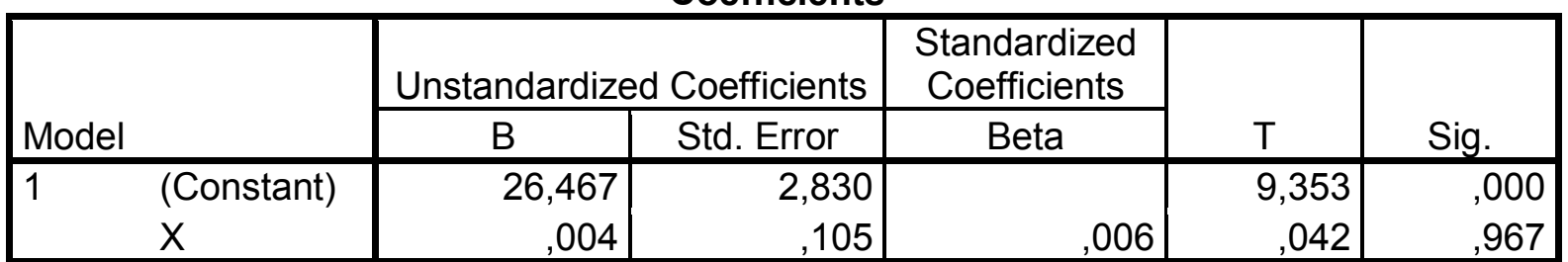

a. Dependent Variable: $Y$

Berdasarkan hasil pengujian diatas, maka diperoleh persamaan regresi linier sederhana sebagai berikut:

$$
\mathrm{Y}=26,467+0,004 \mathrm{X}
$$

Pada model regresi linier sederhana di peroleh nilai konstanta keputusan pembelian sebesar 26,467 artinya jika nilai variabel (X) nilainya 0 , maka variabel terikat (Y) nilainya sebesar 26,467. Koefisien regresi masing-masing variabel bebas bernilai positif, artinya iklan sepeda motor Yamaha dapat mempengaruhi oleh citra merek

\section{Pengujian Hipotesis}

a. Koefisien Determinasi $\left(\mathrm{R}^{2}\right)$

Koefisien determinasi bertujuan untuk mengukur berapa besar kemampuan variabel bebas dalam menerangkan variabel terkait. Nilai koefisien determinasi dapat dilihat pada tabel berikut:

Tabel Hasil Uji Koefisien Determinasi $\left(\mathrm{R}^{2}\right)$

\section{Model Summary}

\begin{tabular}{|l|c|r|r|r|}
\hline Model & $\mathrm{R}$ & $\mathrm{R}$ Square & $\begin{array}{c}\text { Adjusted R } \\
\text { Square }\end{array}$ & $\begin{array}{c}\text { Std. Error of } \\
\text { the Estimate }\end{array}$ \\
\hline 1 &, $006^{\mathrm{a}}$ &, 000 &,- 020 & 1,830 \\
\hline
\end{tabular}

a. Predictors: (Constant), $\mathrm{X}$

Nilai koefisien determinasi yang diperoleh 0.000 atau $0 \%$, menunjukkan bahwa variabel iklan memiliki kontribusi yang sangat kecil yaitu sebesar $0 \%$ terhadap citra merek pada sepeda motor Yamaha, variabel lain yang tidak diteliti dalam penelitian ini.

\section{b. Uji Parsial (uji t)} Kriteria:

Uji parsial (uji t) bertujuan untuk melihat pengaruh iklan terhadap citra merek dengan

1. Jika $t_{\text {hitung }} \leq t_{\text {tabel }}$ maka $H_{0}$ diterima, $H_{1}$ ditolak, artinya secara parsial penelitian ini tidak berpengaruh. 
2. Jika $\mathrm{t}_{\text {hitung }}>\mathrm{t}_{\text {tabel }}$ maka $\mathrm{H}_{0}$ ditolak, $\mathrm{H}_{1}$ diterima, artinya secara parsial penelitian ini berpengaruh.

Coefficients $^{\mathrm{a}}$

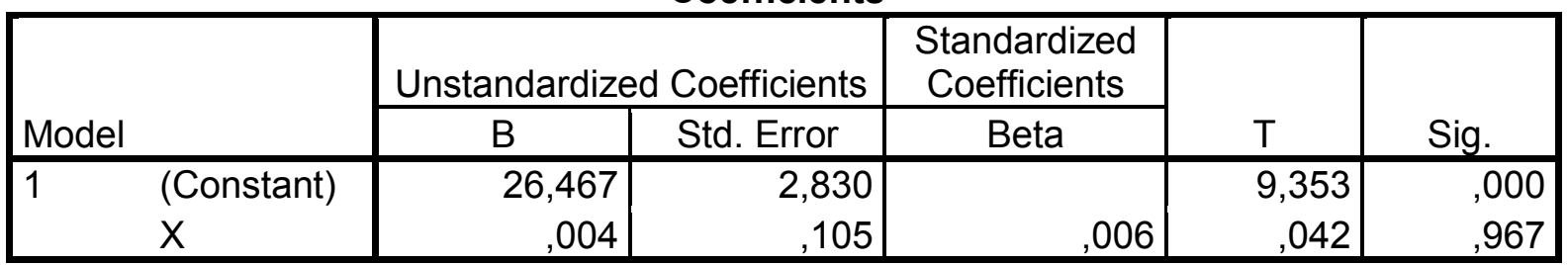

a. Dependent Variable: $Y$

Berdasarkan tabel tersebut dapat dilihat bahwa:

Nilai $\mathrm{t}_{\text {hitung }}$ untuk variabel iklan sebesar $0.042<\mathrm{t}_{\text {tabel }} 2.007$ dan nilai signifikan 0,967 $>$ dari alpha 0,05 , maka $\mathrm{H}_{0}$ diterima dan $\mathrm{H}_{1}$ ditolak dengan demikian secara parsial variabel iklan tidak berpengaruh terhadap citra merek

\section{Pembahasan}

Hasil pengujian hipotesis pertama menunjukkan bahwa variabel iklan tidak mampu menjelaskan variasi yang terjadi pada citra merek pada Politeknik LP3I Medan unit Marelan, ini dibuktikan dengan nilai koefisien determinasi $\mathrm{R}^{2}$ yang diperoleh sebesar 0,042 atau $42 \%$, sedangkan sisanya sebesar 58\% dijelaskan oleh variabel lain yang tidak diteliti oleh penelitin ini.

Dengan hasil ini, iklan sepeda motor Yamaha di Politeknik LP3I Medan unit Marelan tidak berpengaruh dalam citra merek yang membandingkan dengan sepeda motor lainnya. Maka hasil ini memberikan gambaran mahasiswa politeknik LP3I Medan unit Marelan tidak membutuhkan hanya satu merek sepeda motor yang mereka gunakan untuk pergi berkualitas dengan persaingan sepeda motor lainnya

\section{KESIMPULAN}

Berdasarkan hasil penelitian dan pembahasan pada bab sebelumnya, maka dapat disimpulkan sebagai berikut:

1. iklan sepeda motor Yamaha di Politeknik LP3I Medan unit Marelan tidak berpengaruh dalam citra merek yang membandingkan dengan sepeda motor lainnya.

2. mahasiswa politeknik LP3I Medan unit Marelan tidak membutuhkan hanya satu merek sepeda motor yang mereka gunakan untuk pergi berkualitas dengan persaingan sepeda motor lainnya

3. Variabel iklan tidak mampu sepenuhnya berpengaruh terhadap citra merek Yamaha 


\section{REFERENCES}

Kotler, Philip., Keller, K. L. (2016). Manajemen Pemasaran : Edisi Kedua belas Jilid 1 (kedua bela). Jakarta Barat: Permata Puri Media.

Limakrisna, Nandan H Ir Dr., Purba, P. T. D. (2017). Manajemen Pemasaran (Kedua). Jakarta: Mitra Wacana Media.

Manap, A. H. (2016). Revolusi Manajemen Pemasaran (Pertama). Jakarta: Mitra Wacana Media.

Sangadji, Mamang Etta Dr., Sopiah, Dr. MM, M. P. (2013). Perilaku Konsumen Pendekatan Praktis Disertai Himpunan Jurnal Penelitian (Pertama). Yogyakarta: CV. ANDI OFFSET.

Sasetyo, Adi Septa., Nawawi, Hussein., Rondonuwu, R. (2012). Pengaruh Daya Tarik Iklan Terhadap Pembentukan Citra Merek Pepsodent. Mahasiswa Universitas Padjajaran, 1.

Situmorang, I. L. (2017). Pengaruh Kualitas Produk dan Iklan Terhadap Citra Merek dan Keputusan Pembelian Produk Kecantikan Merek Pond's pada Remaja di kota Pekanbaru. JOM Fekon, Vol. 4.

Sudaryono, D. (2016). Manajemen Pemasaran Teori dan Implementasi (pertama). Yogyakarta: C.v Andi Offset.

Sujarweni, W. V. (2015). Metode Penelitian-Bisni \& Ekonomi (pertama). Yogyakarta: Pustaka Barupress.

Sulistyari, I. N. (2012). Analisis Pengaruh Citra Merek, Kualitas Produk, dan Harga Terhadap Minat Beli Produk Oriflame.

Sunyoto, D. D. (2015). Perilaku Konsumen dan Pemasaran (Pertama). Jakarta: CAPS (Center of Academic Publishing Service).

Tjiptono, F. (2015). Strategi Pemasaran (4th ed.). Yogyakarta: Andi Offset.

Trijono, R. (2015). Metodologi Penelitian Kuantitatif(1st ed.). Depok Timur: Papas Sinar Sinanti. 